Ihab Kaddoura, Benjamin Kickhöfer, Andreas Neumann, Alejandro Tirachini

\title{
Agent-based optimisation of public transport supply and pricing: impacts of activity scheduling decisions and simulation randomness
}

Journal article | Accepted manuscript (Postprint)

This version is available at https://doi.org/10.14279/depositonce-9167

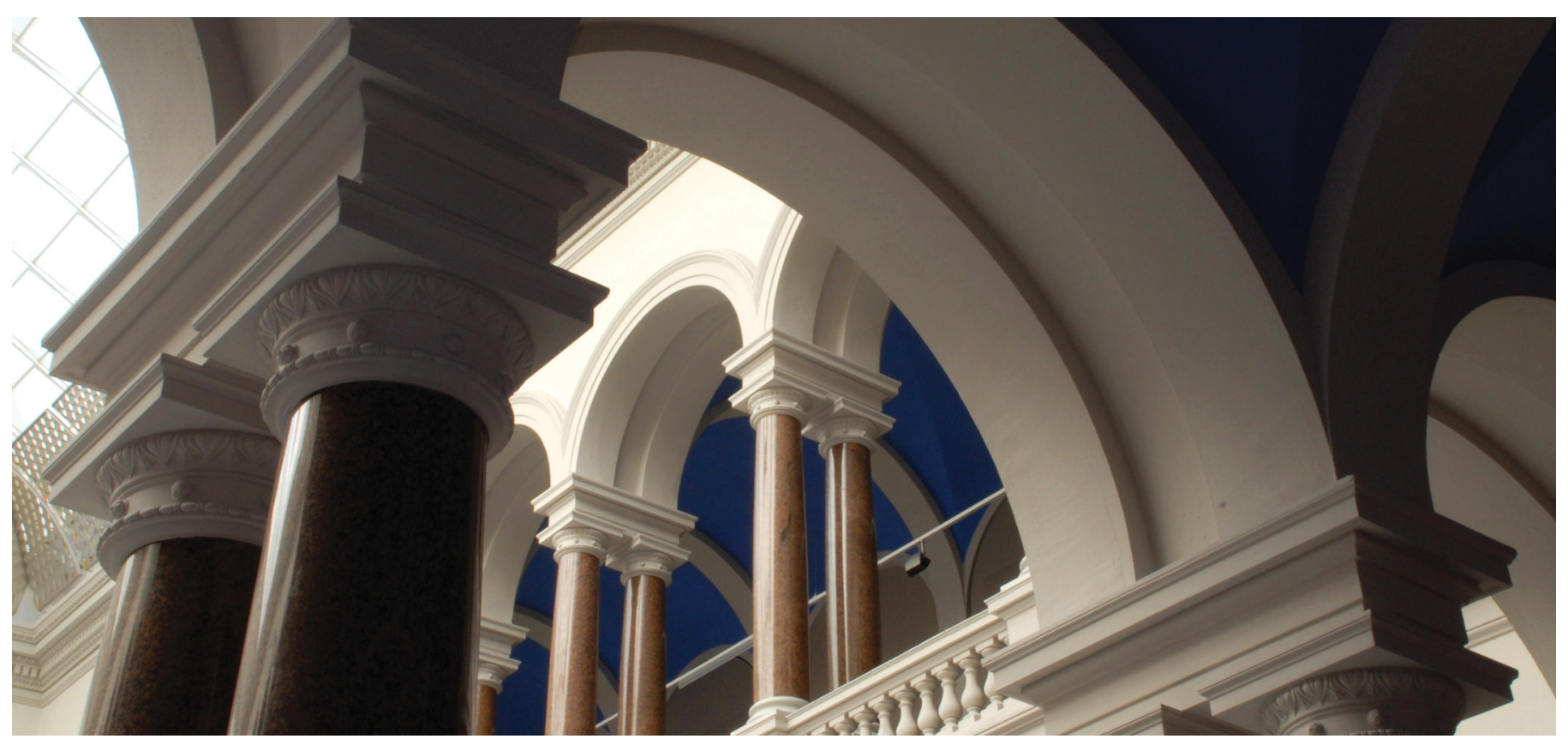

This is a post-peer-review, pre-copyedit version of an article published in Transportation. The final authenticated version is available online at: http://dx.doi.org/10.1007/s11116-014-9533-6.

Kaddoura, I., Kickhöfer, B., Neumann, A., \& Tirachini, A. (2014). Agent-based optimisation of public transport supply and pricing: impacts of activity scheduling decisions and simulation randomness. Transportation, 42(6), 1039-1061. https://doi.org/10.1007/s11116-014-9533-6 


\title{
Agent-based optimisation of public transport supply and pricing: Impacts of activity scheduling decisions and simulation randomness
}

\author{
Ihab Kaddoura • Benjamin Kickhöfer • \\ Andreas Neumann · Alejandro Tirachini
}

Received: date / Accepted: date

Preferred citation style: Kaddoura, I.; Kickhöfer, B.; Neumann, A. and A. Tirachini (2015). "Agent-based optimisation of public transport supply and pricing: Impacts of activity scheduling decisions and simulation randomness". In: Transportation, 42, pp. 1039-1061. DOI: http://dx.doi.org/10.1007/s11116-014-9533-6.

\begin{abstract}
The optimal setting of public transport pricing and supply levels has been traditionally analysed with analytical models that combine the objectives of users, service providers and decision makers in optimisation problems. In this paper, public transport fare and headway are jointly optimised using an activity-based simulation framework. Unlike traditional analytical models that find single optimal values for headway, fare and other optimisation variables, we obtain a range of values for the optimal fare and headway, due to the randomness in user behaviour that is inherent to an agent-based approach. Waiting times and implications of an active bus capacity constraint are obtained on an agent-by-agent basis. The maximisation of operator profit or social welfare result in different combinations of the most likely optimal headway and fare. We show that the gap between welfare and profit optimal solutions is smaller when users can adjust their departure time according to their activities, timetabling and convenience of the public transport service.

I. Kaddoura · B. Kickhöfer · A. Neumann

Department of Transportation System Planning and Telematics

Technische Universität Berlin, Sekr. SG 12, Salzufer 17-19, 10587 Berlin, Germany.

Tel.: +49-30-31478793

Fax: +49-30-31426269

E-mail: kaddoura@vsp.tu-berlin.de

A. Tirachini

Transport Engineering Division, Civil Engineering Department

Universidad de Chile, Santiago, Chile
\end{abstract}


Keywords agent-based simulation - randomness · public transport supply · optimal pricing $\cdot$ social welfare $\cdot$ operator profit

\section{Introduction}

It is estimated that metropolitan areas will continue to contribute a large proportion of a country's economic power and will thus attract people from rural areas. By the year 2030, more than 60 percent of the world's population is expected to be living in major cities. Therefore, the relevance of public transport as a provider of accessibility to services and workplaces is expected to grow, especially considering its role in reducing congestion and the land consumption of the transport sector in urban areas (Nelson et al. 2007). Most municipalities, in both developed and developing countries, need policy advice on how to invest scarce public resources the most efficient way.

This paper is concerned with the optimal setting of public transport pricing and supply levels in urban settings. This challenge has usually been addressed with analytical models, which have the advantage of deriving general principles that can be applied to different situations. Mohring (1972) developed a microeconomic model for identifying the optimal headway for a single bus route with parametric demand, finding that bus frequency (the inverse of headway) should increase less than proportionally with demand. The same paper introduced the idea of total cost minimisation (encompassing users and operator cost); Mohring (1972)'s model has been improved by many researchers, accounting for several extensions such as differences in peak/off-peak demand (Jansson 1980), crowding (Oldfield and Bly 1988; Kraus 1991; Jara-Díaz and Gschwender 2003), bus congestion and the choice of fare collection technologies (Tirachini and Hensher 2011) and the consideration of simplified networks (Chang and Schonfeld 1991).

Elastic demand and mode choice (public vs. private transport) have also received considerable attention in the literature. Several authors have developed models to obtain first best and second best public transport fare and supply levels, including rules for optimal frequency and capacity of the public transport mode (Dodgson and Topham 1987; de Borger and Wouters 1998; Arnott and Yan 2000; Pels and Verhoef 2007; Parry and Small 2009; Ahn 2009; Jansson 2010; Basso et al. 2011; Tirachini and Hensher 2012). These models are suitable to understand the economic principles behind the setting of key variables such as bus frequency, transport capacity and density of lines. However, due to their simplified nature they are less appropriate to handle large-scale scenarios, the representation of demand is very simple (usually, a number of passengers or trips per hour), and activity scheduling decisions (e.g., departure time choice) are generally not accounted for. Consequently, the relationship between departure time choice by users and public transport supply variables such as bus frequency and fare is not clearly understood. A couple of exceptions are Kraus and Yoshida (2002) and Kraus (2003), who introduce departure time choice for public transport users in analytical frameworks that 
borrow the highway bottleneck model of Vickrey (1969) for the modelling of rail commuting, assuming that users arrive at stations at the same time as trains do.

A common element of all analytical models (static and dynamic) of public transport supply and fare setting is that unique values for fare, headway and other optimisation variables are obtained, because these models do not account for randomness in users decisions regarding day-to-day activity scheduling, which in turn affects modal and departure time choices. Simulation models in which the arrival of passengers at bus stops is random have been proposed (e.g., Fernández and Tyler (2005); Fernández (2010); Baskaran and Krishnaiah (2012)); these models are concerned with analysing the performance of the bus service but are not meant to determine the effect of supply decisions on demand, because the latter is insensitive to the quality of service and the possibility of switching departure time is not considered. A change of bus headway and/or fare does have an impact on the decisions of users, who may replan their whole plan for a day (including transport, work and leisure activities) to adapt to the new scenario. For example, a general reduction in bus fare may push a bus passenger to switch from a peak to an off-peak period if, due to the fare reduction, buses get crowded on the peak and the user needs to wait a long time to be able to board a bus.

In this paper, we analyse optimal public transport service provision using the open-source activity-based microsimulation model MATSim ${ }^{1}$. An activitybased simulation approach is well suited for a more realistic representation of both, demand (by allowing users to adapt their activity schedules) and supply (by using the user-by-user dynamic congestion approach embedded in the agent-based MATSim framework). At the same time, the simulation is easy to use; without changing the framework, a scenario can be set up and the simulation can be run. Complex behaviour emerges from simple rules that are easy to understand. Furthermore, the approach is suitable to simulate several scenarios assuming randomness in transport related decisions by users, with the objective of analysing the sensitivity of optimal levels of public transport fare and supply to such randomness.

Unlike analytical models, the activity-based simulation approach allows for an increased level of detail and complexity, and is still easy to use. The maximisation of social welfare and operator profit are studied in a framework that integrates departure time choice and modal choice. Bus headway and fare are jointly optimised using a parametric approach. The cases in which users can and cannot adapt departure times to changes introduced by the public transport provider are separately analysed. We consider that the limited capacity of buses increases waiting time if a passenger cannot board a full bus; the agentbased nature of our model allows us to identify the exact time in which each passenger boards a bus. Dwell times increase with the number of passengers boarding and alighting.

Randomness in user behaviour is inherent to the applied simulation approach.

1 Multi-Agent Transport Simulation, see www.matsim.org 
Therefore, in this paper, the impact of randomness on the results is analysed. Running the simulation with several initial random seeds leads to a range of possible values for the optimal fare and headway when maximising social welfare, with a more likely optimal solution given by the average welfare. This range or interval of potential welfare maximising fares and headways is in contrast of traditional analytical models that find single optimal values for headway, fare and other optimisation variables, and require sensitivity analysis to explore the stability of the solution. If this finding holds when the simulation is run over a real world network, and depending on the characteristics of the the social welfare function around the optimum, the obtained interval can give decision makers the opportunity to decide on fares and headways within a specific range. Therefore, the potential of this approach is that other possible objectives can be included, such as to maximise public transport demand, or to reduce the subsidy to the operation of the public transport service. The maximisation of operator profit and social welfare result in different combinations of the optimal headway and fare (average over several random seeds), as previously found in some microeconomic models (e.g., Chang and Schonfeld (1991); Pels and Verhoef (2007); Ahn (2009)). The novelty of our approach is that it shows how the gap between welfare and profit maximising headways and fares is smaller when commuters can adjust their departure time. Without departure time choice the alternative car mode is increasingly congested which results in a lower price elasticity of public transport demand.

The remainder of this paper is structured as follows: Sec. 2 describes the agentbased microsimulation framework, including an overview of public transport modelling. In Sec. 3 the test scenario is described along with the modelling approach and all relevant assumptions. Results are presented and discussed in Sec. 4. Finally, Sec. 5 summarises the main findings and contributions of this paper and provides venues for further research.

\section{Methodology}

This section (i) gives a brief overview of the general simulation approach of MATSim and (ii) shortly describes special characteristics of the public transport simulation. For in-depth information of the simulation framework MATSim see Raney and Nagel (2006).

\subsection{MATSim Overview}

In MATSim, each traveler of the real system is modelled as an individual agent. The approach consists of an iterative loop that has the following steps:

1. Plans generation: All agents independently generate daily plans that encode among other things their desired activities during a typical day as well as the transport mode for every intervening trip. 
2. Traffic flow simulation: All selected plans are simultaneously executed in the simulation of the physical system. The traffic flow simulation is implemented as a queue simulation, where each road segment (=link) is represented as a first-in first-out queue with two restrictions (Gawron 1998; Cetin et al. 2003): First, each agent has to remain for a certain time on the link, corresponding to the free speed travel time. Second, a link storage capacity is defined which limits the number of vehicles on the link; if it is filled up, no more agents can enter this link.

3. Evaluating plans: All executed plans are evaluated by a utility function which in this paper encodes the perception of travel time and monetary costs for car and bus. For bus, the utility function also accounts for waiting, access, and egress times.

4. Learning: Some agents obtain new plans for the next iteration by modifying copies of existing plans. This modification is done by several strategy modules that correspond to the available choice dimensions. In the present paper, agents can switch between the modes car and bus. In the model with time choice, agents can additionally adapt their departure times. The choice between different plans is performed with respect to a multinomial logit model. As the number of plans is limited for every agent by memory constraints, the plan with the worst performance is discarded when a new plan is added to a person which already has the maximum number of plans permitted.

The repetition of the iteration cycle coupled with the agent database enables the agents to improve their plans over many iterations. This is why it is also called learning mechanism. The iteration cycle continues until the system has reached an approximate stochastic user equilibrium. At this point, there is no quantitative measure of when the system has reached that relaxed state; we just allow the cycle to continue until the outcome is stable.

The iterative loop described above requires a random seed that has to be provided as an input variable. Based on this random seed every iteration a new random seed is generated which is used for drawing (pseudo-)random numbers. Each iteration these numbers determine (a) if an agent is meant to obtain a new plan, (b) which plan is supposed to be modified and executed, (c) how a strategy module modifies a plan (e.g., which activity is to be rescheduled and how the departure time is shifted) and (d) if no plan is modified which plan is individually selected and executed (according to the multinomial logit model probabilities). That means randomness is of great importance when choice sets are generated and when choosing among the options in the choice set. As the entire generated randomness (the sequence of random drawings) depends on the initial random seed, results can be reproduced. The stochastic error terms are fixed and therefore different outcomes before and after introducing a policy measure (e.g., increasing the headway) can only be the result of the measure itself (Horni et al. 2011, 2012). 


\subsection{Public Transport in MATSim}

In MATSim, a transit schedule provides all planned public transport operations. Actual vehicle departures may differ from the schedule as transit vehicles are simulated in the traffic flow simulation and interact with boarding and alighting passengers. Depending on the vehicle type each passenger can delay the transit vehicle. In this study, passengers are boarding and alighting simultaneously at different doors. Thus, the total vehicle delay is defined by the maximum of the total boarding delay and the total alighting delay. A vehicle fully loaded cannot pick up any more passengers, in that case passengers will have to wait for the next vehicle to arrive. Vehicles of one line can serve different tours. Consequently, the delay of one vehicle can be transferred to the following tour. In the case of a delay, the driver will try to follow the schedule by shortening dwell times (if no person wants to alight or board) as well as slack times. MATSim's public transport simulation also allows for private cars and buses competing for the same limited road capacity. Each stop can be configured to either block traffic or to allow overtaking whenever a bus stops. However, in this study, we do not assume a mixed-traffic operation, thus, transit vehicles are not affected by traffic congestion. For an in-depth description of MATSim's public transport dynamics refer to Neumann and Nagel (2010) and Rieser (2010).

\section{Scenario: Multi-Modal Corridor}

\subsection{Setup}

Supply The interaction of supply and demand is modelled for a multi-modal corridor with a total length of $20 \mathrm{~km}$. From 4 a.m. until midnight, the corridor is served by a constant number of identical buses that are operated by a single company. Transit stops are located at a regular distance of $500 \mathrm{~m}$ along the corridor. Access and egress times result from a walk speed of $4 \mathrm{~km} / \mathrm{h}$ and the distances between transit stop and activity location. A free speed of $30 \mathrm{~km} / \mathrm{h}$, a minimum dwell time of $10 \mathrm{sec}$ at each transit stop, and a slack time of $5 \mathrm{~min}$ when reaching a corridor endpoint amounts to a cycle time of $1 \mathrm{~h} 43 \mathrm{~min}$. Actual cycle times and headways can differ from the schedule when demand is high due to vehicle-passenger interactions. Passengers are assumed to be able to alight and board at the same time (see Sec. 2.2). Boarding time is set to 2 sec per person (obtained with a boarding system with contactless card fare payment, (Wright and Hook 2007)) and alighting times to 1.5 sec per person. As described in Sec. 2.2, the transit driver will try to follow the schedule by shortening the fixed component of dwell times (if no one wants to board or alight), as well as slack times. In this study, the scheduled slack time at the terminus is sufficient high to compensate for the remaining delay. Therefore, delays are not propagated from one tour to another.

We assume that the road has two lanes per direction, with buses running on 
a separate bus lane, therefore they are not affected by traffic congestion. Car travel times are subject to dynamic congestion. The flow capacity of a lane is $1,000 \mathrm{pcu} / \mathrm{h}$ (pcu: passenger car unit), equivalent to assuming a saturation flow of $2,000 \mathrm{pcu} / \mathrm{h}$ and and effective green time ratio of 50 percent in a signalised intersection.

Demand Activity patterns for a total of 20,000 travelers are considered with a random distribution of activity locations along the corridor. Two types of activity patterns are considered, defined by trip purpose: "Home-Work-Home", which is assumed to represent $35 \%$ of total trips, and "Home-Other-Home", which accounts for $65 \%$ of trips. In this study, these activity patterns are fixed, that is, the agents neither change their activity types nor their order of activities. Regarding departure time adaptation, two possibilities are modelled:

- No departure time adaptation (NDTA). Agents have the initially given departure times and a fixed activity schedule.

- Total departure time adaptation (TDTA). Agents can adjust their departure times according to activity specific constraints. Activity types "Work" and "Other" have defined opening times, whereas "Home" can always be performed. As commuters and non-commuters are assumed to have wide time spans of arrival, activity schedules are flexible (see Tab. 1).

Different distributions are assumed for the departure time of work and nonwork trips. Initial departure times from activity "Home" to "Work" follow a normal distribution with mean at 8 a.m. and a standard deviation of $1 \mathrm{~h}$. Agents are assumed to head back home $8 \mathrm{~h}$ after starting work. The activity type "Other" has a duration of $2 \mathrm{~h}$ and is uniformly distributed from 8 a.m. to $8 \mathrm{p} . \mathrm{m}$. This is a desired departure time distribution in the TDTA case, in which users can change departure times to avoid congestion. Initial modal split for all trips is $50 \%$ car and $50 \%$ bus. The overlay of peak and off-peak demand (both activity patterns) is shown in Fig. 1.

The agents' activity schedules described above are of synthetic nature. However, trip purposes (commuters vs. non-commuters), activity durations and activity opening and closing times are chosen to reflect trip distributions that can be found in reality (Fig. 1). The motivation is to create a simple test scenario with enough complexity to study the issue of public transport supply optimisation with an activity-based simulation approach.

\subsection{Simulation Approach}

\subsubsection{Users}

Choice Dimensions For the mental layer within MATSim which describes the behavioural learning of agents, a simple utility based approach is used. When choosing between different options with respect to a multinomial logit model, agents are allowed to adjust their behaviour among the following choice dimensions: 


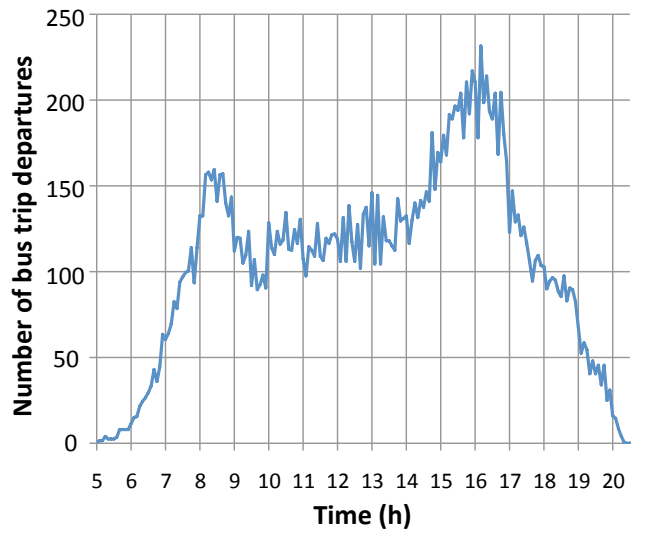

Fig. 1: Initial departure time distribution

- Mode choice allows to choose the mode of transport for a sub-tour within an agent's daily plan. Agents can switch from car to public transport or the other way around. In this paper it is assumed that every agent has a car available.

- Time choice allows to adapt departure times in order to shift, extend or shorten activity durations with respect to activity specific attributes described in the following paragraph (TDTA case only).

Utility Functions The total utility (deterministic part) that an executed plan gets is the sum of individual contributions:

$$
V_{p}=\sum_{i=1}^{n}\left(V_{p e r f, i}+V_{t r, i}\right),
$$

where $V_{p}$ is the total utility for a given plan; $n$ is the number of activities; $V_{\text {perf }, i}$ is the (positive) utility earned for performing activity $i$; and $V_{t r, i}$ is the (usually negative) utility earned for traveling to activity $i$. Activities are assumed to wrap around the 24-hours-period, that is, the first and the last activity are stitched together. In consequence, there are as many trips between activities as there are activities. The functional form of the travel related utility functions is as follows:

$$
\begin{aligned}
V_{p t, i, j} & =\beta_{v, p t} \cdot t_{i, v, p t}+\beta_{w, p t} \cdot t_{i, w, p t}+\beta_{a, p t} \cdot t_{i, a, p t}+\beta_{e, p t} \cdot t_{i, e, p t}+\beta_{c} \cdot c_{i, p t} \\
V_{c a r, i, j} & =\beta_{0}+\beta_{t r, c a r} \cdot t_{i, t r, c a r}+\beta_{c} \cdot c_{i, c a r}
\end{aligned}
$$

where $V$ is the systematic part of utility for person $j$ on her trip to activity $i$. It is computed in "utils" and in the present paper mode dependent as indicated by the indices car and $p t$. The travel time $\left(t_{i, t r, c a r}\right)$ and monetary distance costs $\left(c_{i, c a r}\right)$ are considered as attributes of a car trip to activity $i$. 
For public transport trips in-vehicle time $\left(t_{i, v, p t}\right)$, waiting time $\left(t_{i, w, p t}\right)$, access time $\left(t_{i, a, p t}\right)$, egress time $\left(t_{i, e, p t}\right)$ and monetary costs $\left(c_{i, p t}\right)$ are considered. A logarithmic form is used for the positive utility earned by performing an activity (Charypar and Nagel 2005; Kickhöfer et al. 2011):

$$
V_{\text {perf }, i}\left(t_{\text {perf }, i}\right)=\beta_{\text {perf }} \cdot t_{*, i} \cdot \ln \left(\frac{t_{\text {perf }, i}}{t_{0, i}}\right),
$$

where $t_{\text {perf }}$ is the actual performed duration of the activity, $t_{*}$ is the "typical" duration of an activity, and $\beta_{\text {perf }}$ is the marginal utility of an activity at its typical duration. $\beta_{\text {perf }}$ is the same for all activities, since in equilibrium all activities at their typical duration need to have the same marginal utility. $t_{0, i}$ is a scaling parameter that is related both to the minimum duration and to the importance of an activity. As long as dropping activities from the plan is not allowed, $t_{0, i}$ has essentially no effect. Activities only can be performed within certain time slots. Thus, agents that arrive early and wait for the activity location to open are penalised by the opportunity costs of time $-\beta_{\text {perf }}$.

Table 1: Activity attributes

\begin{tabular}{llll}
\hline Activity & Typical Duration & Opening Time & Closing Time \\
\hline \hline Home & $12 \mathrm{~h}$ & undefined & undefined \\
Work & $8 \mathrm{~h}$ & 6 a.m. & $8 \mathrm{p} . \mathrm{m}$. \\
Other & $2 \mathrm{~h}$ & $8 \mathrm{a} . \mathrm{m}$. & $8 \mathrm{p} . \mathrm{m}$. \\
\hline
\end{tabular}

Parameters Behavioural parameters for the utility function are based on an Australian study by Tirachini et al. (2014). Estimated parameters ${ }^{2}$ and Values of Travel Time Savings (VTTS) are depicted in Tab. 2. The estimated value for $\beta_{e, p t}$ yields a VTTS for egress of $\$ 53.23$ which is implausible high. Since egress times are - in the present scenario - constant, $\beta_{e, p t}$ is set to be equal to the access time parameter $\beta_{a, p t}$. Splitting the time related parameters into opportunity costs of time and an additional mode specific disutility of traveling Kickhöfer et al. (2011, 2012, in press), leads to the parameters in Tab. 3 which match the MATSim framework. While car users in reality have to find a parking lot and also need to walk from the parking lot to the desired activity location, in the model they can directly enter and leave their vehicles at the activity location and immediately start an activity. To compensate for a to attractive car mode the alternative specific constant $\beta_{0}$ for car was recalibrated for the synthetic corridor scenario. An urban scenario is assumed in which a modal split of around 50\%:50\% between car and bus is obtained if the bus service is provided with 6 min 26 sec headway and a fare of $\$ 1.50$ (see later on in Fig. $3 \mathrm{~b}$ ). The outcome of the calibration process is an alternative specific constant for car of $\beta_{0}=-0.15 . c_{i, c a r}$ is calculated for every trip by

2 Estimated parameters are in this paper flagged by a hat. 
Table 2: Parameters and VTTS taken from Tirachini et al. (2014)

\begin{tabular}{lll}
\hline \hline$\hat{\beta}_{t r, c a r}$ & -0.96 & {$[$ utils $/ \mathrm{h}]$} \\
$\hat{\beta}_{v, p t}$ & -1.14 & {$[$ utils $/ \mathrm{h}]$} \\
$\hat{\beta}_{w, p t}$ & -1.056 & {$[$ utils $/ \mathrm{h}]$} \\
$\hat{\beta}_{a, p t}$ & -0.96 & {$[$ utils $/ \mathrm{h}]$} \\
$\hat{\beta}_{e, p t}$ & -3.3 & {$[$ utils $/ \mathrm{h}]$} \\
$\hat{\beta}_{c}$ & -0.062 & {$\left[\right.$ utils $\left./ \$^{a}\right]$} \\
\hline$\hat{\beta}_{p e r f}$ & n.a. & {$[\mathrm{utils} / \mathrm{h}]$} \\
\hline \hline$V T T S_{t r, c a r}$ & 15.48 & {$[\$ / \mathrm{h}]$} \\
$V T T S_{v, p t}$ & 18.39 & {$[\$ / \mathrm{h}]$} \\
$V T T S_{w, p t}$ & 17.03 & {$[\$ / \mathrm{h}]$} \\
$V T T S_{a, p t}$ & 15.48 & {$[\$ / \mathrm{h}]$} \\
$V T T S_{e, p t}$ & 53.23 & {$[\$ / \mathrm{h}]$} \\
\hline
\end{tabular}

Table 3: Adjusted parameters and VTTS used in the present paper

\begin{tabular}{lll}
\hline \hline$\beta_{t r, c a r}$ & 0 & {$[$ utils $/ \mathrm{h}]$} \\
$\beta_{v, p t}$ & -0.18 & {$[$ utils $/ \mathrm{h}]$} \\
$\beta_{w, p t}$ & -0.096 & {$[\mathrm{utils} / \mathrm{h}]$} \\
$\beta_{a, p t}$ & 0 & {$[\mathrm{utils} / \mathrm{h}]$} \\
$\beta_{e, p t}$ & 0 & {$[\mathrm{utils} / \mathrm{h}]$} \\
$\beta_{c}$ & -0.062 & {$[\mathrm{utils} / \$]$} \\
\hline$\beta_{p e r f}$ & +0.96 & {$[\mathrm{utils} / \mathrm{h}]$} \\
\hline \hline$V T T S_{t r, c a r}$ & 15.48 & {$[\$ / \mathrm{h}]$} \\
$V T T S_{v, p t}$ & 18.39 & {$[\$ / \mathrm{h}]$} \\
$V T T S_{w, p t}$ & 17.03 & {$[\$ / \mathrm{h}]$} \\
$V T T S_{a, p t}$ & 15.48 & {$[\$ / \mathrm{h}]$} \\
$V T T S_{e, p t}$ & 15.48 & {$[\$ / \mathrm{h}]$} \\
\hline
\end{tabular}

$a \quad \$$ is Australian Dollar (AUD), AUD $1.00=$ EUR 0.69 (July 2014)

multiplying the distance between the locations of activity $i-1$ and $i$ by a distance cost rate of $0.40 \$ / \mathrm{km} . c_{i, p t}$ is the fare which is a flat fee that has to be paid every time an agent is boarding a bus.

\subsubsection{Operator's Profit and Social Welfare}

Total operator cost $(C)$ is calculated as equation (4):

$$
C=\left(v k m \cdot c_{v k m}+v h \cdot c_{v h}\right) \cdot O+v N r \cdot c_{v d a y}
$$

In equation (4), $\mathrm{C}$ is divided into three categories: vehicle kilometers $(v k m)$, vehicle hours $(v h)$ and an overhead $(O)$ including operating costs which are not covered in the other categories. Capital costs for vehicles result from the number of vehicles $(v N r)$ engaged per day and equivalent daily capital costs $\left(c_{v \text { day }}\right)$. Unit costs per vkm $\left(c_{v k m}\right)$, unit costs per vh $\left(c_{v h}\right)$, the overhead and capital costs are based on estimations by ATC (2006) for urban regions in Australia. Unit costs per vkm and capital costs depend on the capacity (seats and standing room); a linear regression analysis yields cost functions implying capital costs between 54 and 199 \$/day and unit costs between 0.62 and $1.13 \$ / \mathrm{vkm}$. The number of public transport trips per day $\left(T_{p t}\right)$ multiplied by a constant fare $(f)$ leads to daily operator's revenues. Hence, operator's profit per day $\left(\Pi_{\text {operator }}\right)$ can be described as follows:

$$
\Pi_{\text {operator }}=T_{p t} \cdot f-C
$$

User benefits are calculated as logsum term or Expected Maximum Utility (EMU) for all choice sets of the users. Social welfare $W$ is measured as the 
sum of operator profit and user benefits per day:

$$
W=\Pi_{\text {operator }}+\sum_{j=1}^{J}\left(\frac{1}{\left|\beta_{c}\right|} \ln \sum_{p=1}^{P} e^{V_{p}}\right),
$$

where $\beta_{c}$ is the cost related parameter of the multinomial logit model or the negative marginal utility of money, $J$ is the number of agents in the population, $P$ is the number of plans or alternatives of individual $j$, and $V_{p}$ is the systematic part of utility of alternative $(=$ plan $) p$.

Table 4: Unit costs and cost functions from ATC (2006)

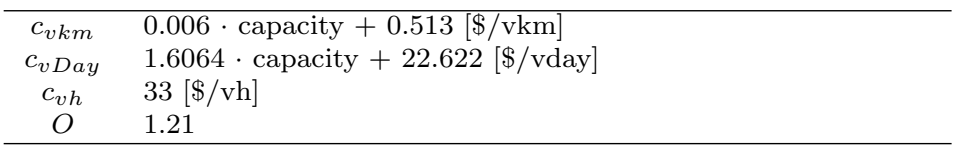

\subsubsection{Simulation Procedure}

A grid search is implemented for the optimisation of bus headway and fare. The iterative loop described in Sec. 2.1 is now embedded into two external loops. In one iteration of external loop 1, fare is kept constant while loop 2 varies the headway. The result is that the constant fare is simulated with every headway of the search space. Then fare is changed in external loop 1, and again simulated with every headway. Independently of headway or fare, the same initial plans are used as input for the internal loop. Here, agents execute their plans simultaneously in the physical environment, evaluate plans according to the utility functions described in Sec. 3.2.1, and modify these plans depending on the available choice dimensions. For the relaxation process described in Sec. 2.1 a total of 300 internal iterations are run, the maximum number of plans per agent is set to 6 and a plan is modified by each strategy module (mode/time choice) with a probability of $10 \%$. After 250 internal iterations the agents are assumed to have a plausible number of different plans in their choice set. Therefore experimental replanning is switched off at this point. For the last 50 iterations agents only chose among their existing plans with respect to a multinomial logit model. The last internal iteration is used for welfare and operator profit calculations as well as for further analyses. Considering the inherent randomness of user decisions and to perform variability analyses, the described simulation process is repeated for different random seeds (see Sec. 2.1). The output parameters (e.g., mode shares, welfare, operator profit) of different random seed runs are then compared and averaged for each combination of headway and fare. 


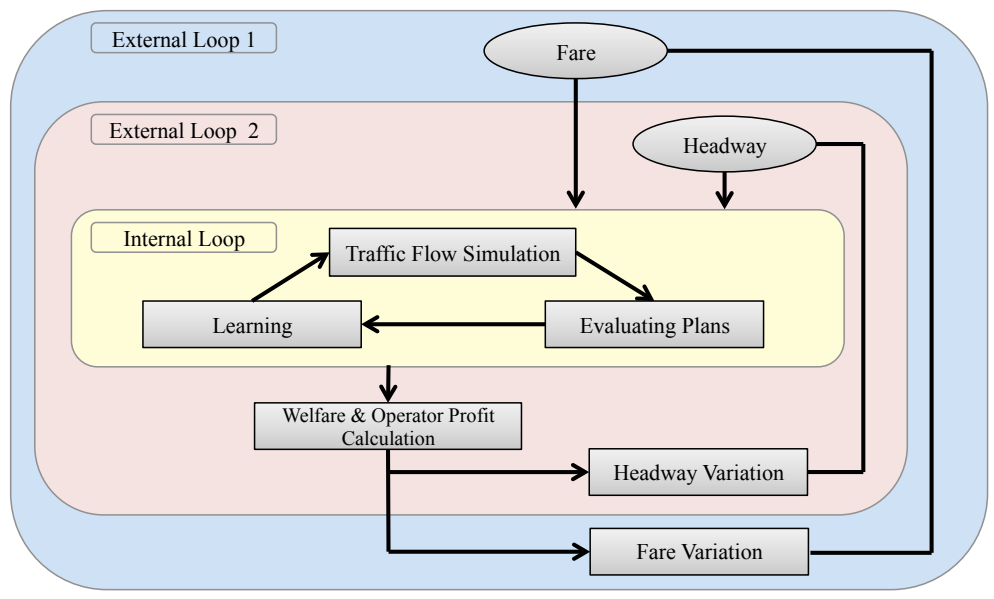

Fig. 2: Simulation Procedure

\section{Results and Discussion}

\subsection{The Influence of Departure Time Choice}

In this section we compare the influence of departure time choice on optimal supply parameters. Buses are not affected by congestion on the road. However, the capacity of buses is fixed to 60 passengers per bus, therefore, the bus mode has a binding capacity constraint. In the joint optimisation process headways are varied from $51 \mathrm{~min} 30 \mathrm{sec}$ to $1 \mathrm{~min} 27 \mathrm{sec}$ by increasing the number of buses. Fares are varied from $\$ 0$ to $\$ 5.00$ in steps of $\$ 0.25$. This grid search process is repeated for 10 different random seeds. Results are given as averages over all simulation runs with different random seeds, unless otherwise indicated. In the model without departure time adaptation (NDTA) the only possible user reaction to a change in supply is mode choice. In the model with total departure time adaptation (TDTA) users can additionally react by shifting departure times.

\subsubsection{Mode Choice}

Fig. 3 depicts the trip share of bus for each combination of headway and fare. In Fig. 3a, the bus modal share is about $50 \%$ (line marked 0.5 in Fig. 3a) from a headway of $8 \mathrm{~min} 35 \mathrm{sec}$ and a fare of $\$ 0$ up to $1 \mathrm{~min} 27 \mathrm{sec}$ and $\$ 1.50$. On the other hand, for the TDTA model, the line marked 0.5 in Fig. 3b is shifted towards the top-left corner, with different combinations of headway and fare: from $11 \mathrm{~min} 26 \mathrm{sec}$ and $\$ 0$ up to $1 \mathrm{~min} 27 \mathrm{sec}$ and $\$ 2.00$. In other words, public transport is more attractive when users have flexibility to adjust their departure times. However, for higher fares and larger headways resulting in lower trip shares of bus (e.g., $5 \%$ ) the opposite effect occurs. The line marked 


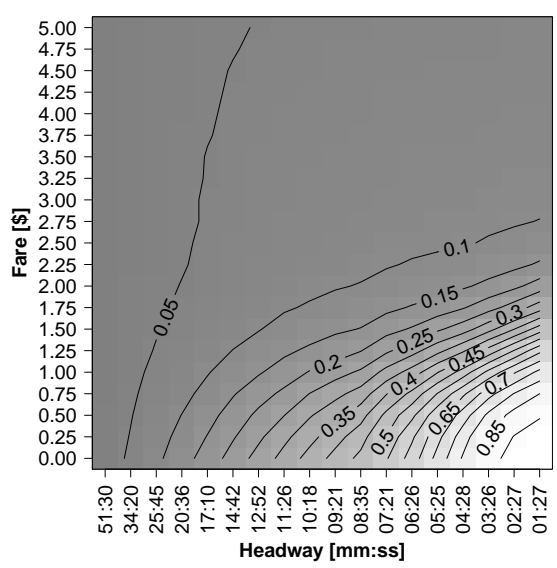

(a) NDTA model

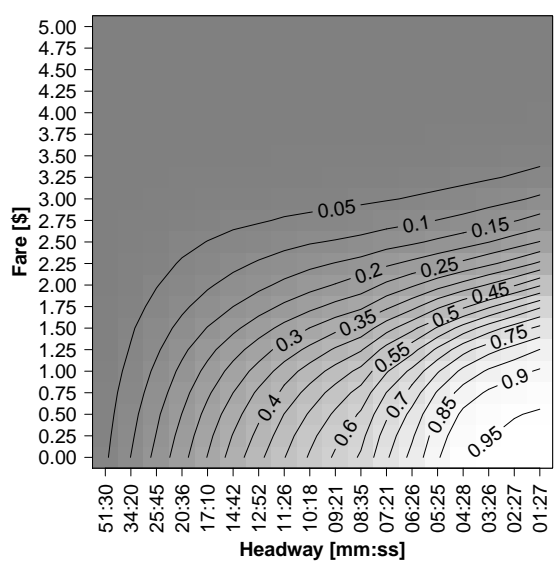

(b) TDTA model

Fig. 3: Trip share of bus (average of all random seed runs)

0.05 is shifted to the bottom-right corner (towards lower fares and shorter headways), indicating that the bus mode is less attractive in the TDTA model. The reason for the latter effect, occurring for a high number of car users, is a more attractive car mode in the TDTA model compared to the NDTA model. In the TDTA model, congested roads are avoided by shifting departure times, but without departure time choice switching to bus is the only way to prevent from being slowed down in a bottleneck. Therefore the bus mode seems to be more attractive in the NDTA model. This effect is emphasised when calculating road congestion for the two models: For the NDTA model, average relative car travel time delays ${ }^{3}$ range from $0.05 \%$ up to $28 \%$. In contrast, the TDTA model only yields average car travel time delays between $0.006 \%$ and $2 \%$.

\subsubsection{Operator Profit and Social Welfare}

Fig. 4 shows the operator profit. In the TDTA model the maximum is within the search space, whereas in the NDTA model the operator profit increases further for larger headways and higher fares that are not investigated (towards the top-left corner).

As expected, in the NDTA model operator profit is positively influenced by headway-fare combinations where car congestion occurs. This is due to the fact that more users accept higher fares and larger headways in order to avoid car congestion. As indicated by the "0"-line in Fig. 4a, break-even fareheadway combinations for the NDTA model range from $\$ 4.00$ and a headway of $51 \mathrm{~min} 30 \mathrm{sec}$ over $\$ 3.50$ and $34 \mathrm{~min} 20 \mathrm{sec}$ to $\$ 5.00$ and $14 \mathrm{~min} 42 \mathrm{sec}$. Global profit maxima are found in the regions between $\$ 4.50$ and $\$ 5.00$ and

\footnotetext{
3 Relative car travel time delays are measured as the ratio between car travel time delay (actual travel time minus free-flow travel time) and total car travel time (average of all car trips and average of all random seeds).
} 


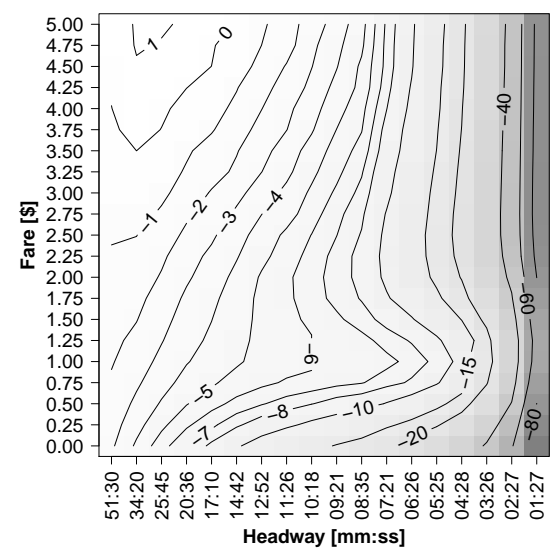

(a) NDTA model

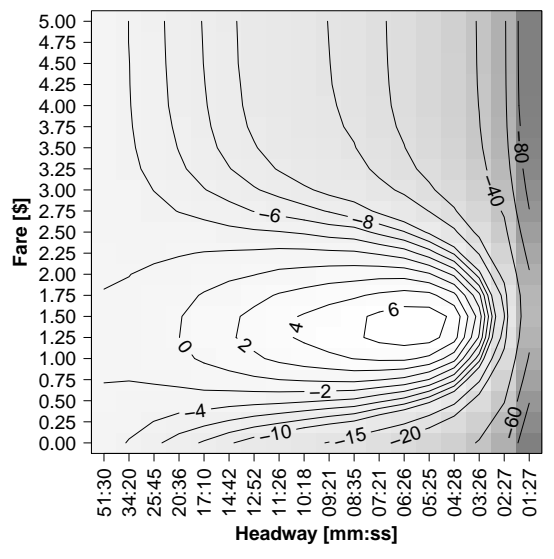

(b) TDTA model

Fig. 4: Operator profit in $\$ 1,000$ (average of all random seed runs)

between a headway of $34 \mathrm{~min} 20 \mathrm{sec}$ and $25 \mathrm{~min} 45 \mathrm{sec}$. The optimal combination of headway and fare for the average profit of all random seeds is equal to the parameters identified for most of the random seeds: $\$ 5.00$ and a headway of 25 min $45 \mathrm{sec}$ yielding an average profit of $\$ 1,198$ (standard deviation: $\sigma=\$ 207)$. As Fig. 4b shows for the TDTA model, the bus operator realises an average profit maximum of $\$ 7,088(\sigma=\$ 137)$ by offering a headway of $5 \mathrm{~min} 25 \mathrm{sec}$ and charging $\$ 1.50$ per trip. At this point the operator profit maximum is found for most of the random seeds. The break-even reaches elliptically from 20 min $36 \mathrm{sec}$ and $\$ 1.25$ over $8 \mathrm{~min} 35 \mathrm{sec}$ and $\$ 0.75,3$ min $26 \mathrm{sec}$ and $\$ 1.50$ to $8 \mathrm{~min} 35 \mathrm{sec}$ and $\$ 2.00$. Fig. 4 can be used to study the effect of a budget constraint on maximum subsidy by restricting the search of feasible fares and headways to those that comply with a given financial constraint. The impact of budget constraints on the setting of public transport fares has been studied by Tabuchi (1993), Ahn (2009), Jara-Díaz and Gschwender (2009) and Basso and Silva (2013), among others.

When comparing the models, two effects become apparent: For low road congestion the operator benefits from users adapting their departure times. That is due to a higher number of bus users for the same headway and fare. However, with heavy road congestion, the bus operator benefits when users cannot adjust departure time, and therefore, are willing to accept longer waiting times and a higher fare. In this case the demand is less elastic and the additional revenues due to higher fares more than compensate for the few users that switch to car. Hence, for the NDTA model, profit maximisation results in a more expensive bus ticket.

Fig. 5 shows the impact of varying headway and fare on the users. Overall, user benefit is for the TDTA model on a higher level than for the NDTA model. As expected, in both models the user benefit increases for shorter headways and lower fares, as the individually obtained utility increases due to lower mone- 
tary costs and shorter travel times as well as users switching from car to bus.

Fig. 6 depicts the social welfare as the sum of user benefits and operator profit, obtained for each parameter combination (average of all random seeds); Fig. 7 shows the standard deviation for each headway and fare. In the TDTA model, the welfare level is above that of the NDTA model. A maximum of $\$ 8,447,645$ for the NDTA model is found for a fare of $\$ 0.50$ and a headway of $4 \mathrm{~min} 28 \mathrm{sec}$ (average of all random seeds, $\sigma=\$ 76$ ). At this point the global maximum is found in most of the runs. Shorter headways above the welfare maximum reduce the operator profit to a larger extent than users benefit from shorter waiting times. In the TDTA model, the same fare but a headway of $3 \mathrm{~min} 26 \mathrm{sec}$ is found to be welfare maximising yielding a social welfare of

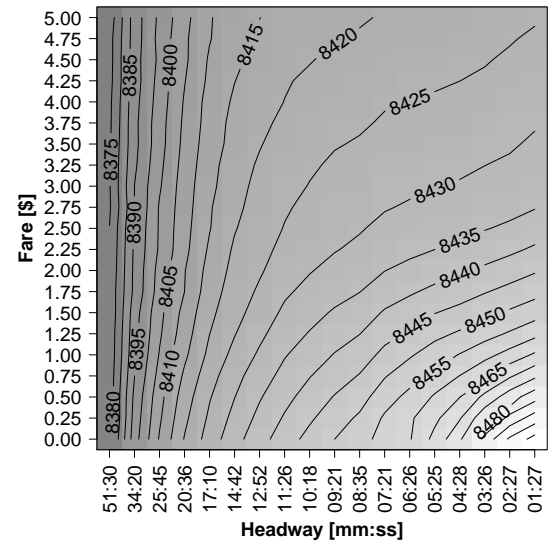

(a) NDTA model

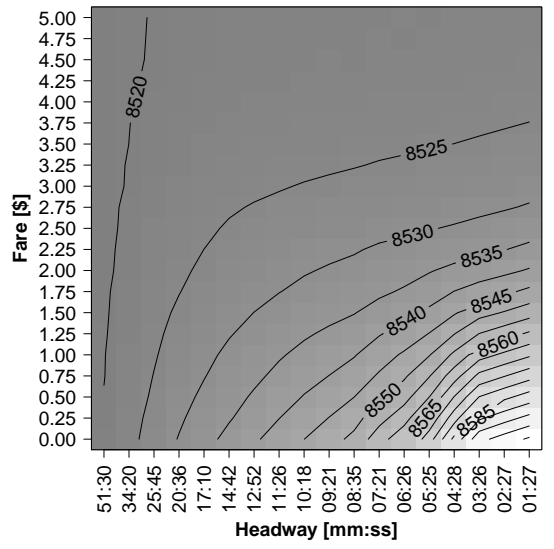

(b) TDTA model

Fig. 5: User benefits in $\$ 1,000$ (average of all random seed runs)

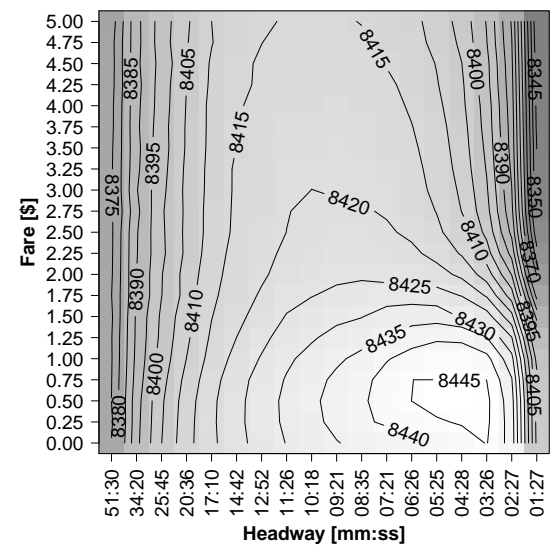

(a) NDTA model

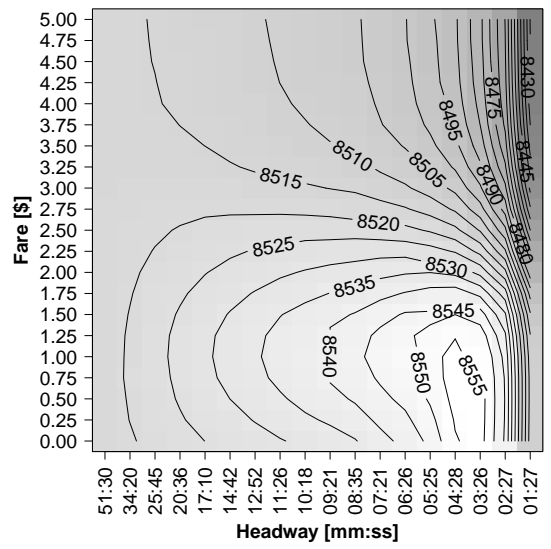

(b) TDTA model

Fig. 6: Social welfare in $\$ 1,000$ (average of all random seed runs) 
$\$ 8,557,438$ (average of all random seeds, $\sigma=\$ 112$ ). Again, in most of the runs this combination of headway and fare is identified as a global maximum. In both models, the standard deviation obtained for the average welfare in the global maximum is relatively small. Whereas, for larger headways and higher fares, especially in the NDTA model, the standard deviation is larger. In both, the NDTA and the TDTA model, the standard deviation increases for headway/fare combinations with a high number of bus users that have to wait longer due to buses working at maximum capacity (compare with Fig. 8). A more detailed analysis of randomness is performed in Sec. 4.2.

Tab. 5 summarises the headway/fare combination for the welfare $(W)$ and the operator profit $\left(\Pi_{\text {operator }}\right)$ optimal solutions in the NDTA and the TDTA model. It also shows the mode shares obtained for each solution (average of all random seeds), including the standard deviation $\sigma$. Furthermore, a budget constraint on maximum subsidy is included, e.g. the optimisation objective of maximum social welfare subject to the constraint that the operator profit is greater or equal $\$ 0.0$. That is, we assume a maximum subsidy of $\$ 0.0$ per day. For this optimisation objective, the NDTA model leads to a headway which is in between that of the profit and welfare maximum. In the TDTA model, both headway and fare are situated in between the welfare and the profit optimal solution. ${ }^{4}$

Comparing the NDTA and TDTA model, two effects are identified: On the one hand, in Fig. 3, a 50\% mode share can be achieved with a larger headway and fare in the TDTA model than in the NDTA model. That is, the ability to reschedule departure times compensates for a larger headway and a higher

4 If not otherwise specified, welfare optimal or welfare maximum refer to the unconstraint situation which also allows for the operator to make losses.

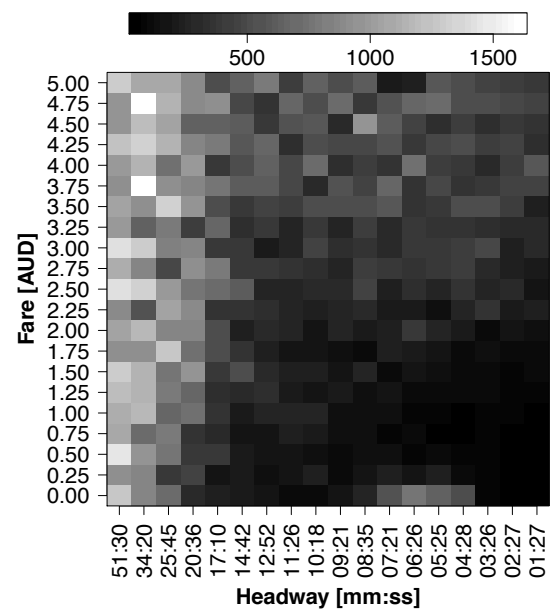

(a) NDTA model

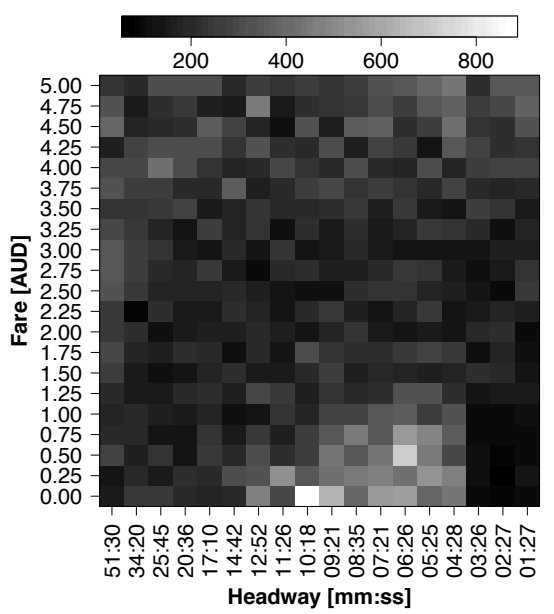

(b) TDTA model

Fig. 7: Standard deviation of average social welfare in $\$$ 
Table 5: Optimal solutions (average of all random seeds)

\begin{tabular}{lll}
\hline & NDTA model & TDTA model \\
\hline \hline $\operatorname{Max}(W)$ & Headway: $4 \mathrm{~min} 28 \mathrm{sec}$ & Headway: $3 \mathrm{~min} 26 \mathrm{sec}$ \\
& Fare: $\$ 0.5$ & Fare: $\$ 0.5$ \\
& Bus share: $72.48 \%(\sigma=0.17 \%)$ & Bus share: $93.73 \%(\sigma=0.10 \%)$ \\
\hline Max $\left(\Pi_{\text {operator }}\right)$ & Headway: $25 \mathrm{~min} 45 \mathrm{sec}$ & Headway: 5 min $25 \mathrm{sec}$ \\
& Fare: $\$ 5.0$ & Fare: $\$ 1.5$ \\
& Bus share: $3.38 \%(\sigma=0.10 \%)$ & Bus share: $55.55 \%(\sigma=0.23 \%)$ \\
\hline $\operatorname{Max}(W)$ & Headway: $17 \mathrm{~min} 10 \mathrm{sec}$ & Headway: $4 \min 28 \mathrm{sec}$ \\
$\Pi_{\text {operator }} \geq 0$ & Fare: $\$ 5.0$ & Fare: $\$ 1.0$ \\
& Bus share: $4.37 \%(\sigma=0.11 \%)$ & Bus share: $81.36 \%(\sigma=0.27 \%)$ \\
\hline
\end{tabular}

fare. On the other hand, if we start in the NDTA global optimum and allow departure time adaptation, the bus mode becomes relatively more attractive (see Tab. 5). Capacity constraints lead to an increase in the number of trips missing at least one bus (see Fig. 8b). Consequently, decreasing headway will increase welfare. At a fare of $\$ 0.50$ and a headway of $3 \mathrm{~min} 26 \mathrm{sec}$, no more buses will be missed. This is also the global welfare maximum (Fig. 6b). Comparing the global welfare and profit maxima, it is evident that operator profit and social welfare maximisation processes result in different combinations of optimal headway and fare, as previously found in several microeconomic models (e.g., Chang and Schonfeld (1991); Pels and Verhoef (2007); Ahn (2009)). The novelty of our approach is that it shows how the gap between welfare and profit maximising headways and fares is smaller when users can adjust their departure time. As described above, without departure time choice the alternative car mode is increasingly congested which results in a lower price elasticity of public transport demand. Furthermore, for headway-fare combinations around the welfare maximum the number of bus users is higher in the TDTA model, meaning that with departure time choice the bus service is more efficient. Thus, the operator and the users benefit from departure time adaptation.

\subsubsection{Constrained Bus Capacity and Optimal Pricing}

Assuming a separated bus lane, buses are not delayed by road congestion. However, public transport users are subject to three types of congestion effects: First, a bus is delayed due to transfers: if more than 5 agents board or more than 7 agents alight at a transit stop the scheduled dwell time is exceeded. As a consequence other passengers are affected due to longer in-vehicle times. Once a bus is fully loaded, it will not be further delayed. Second, as in each external iteration the number of buses is fixed, an increase in dwell time at stops due to a large number of passengers boarding and/or alighting also increases the actual bus headway, on top of the scheduled headway. Therefore, the average cost of waiting times increases. Third, if buses are working at maximum capacity, users cannot board and thus have to wait for a later 
bus, further increasing waiting time.

These effects explain why for some levels of supply, welfare maximising fares higher than $\$ 0$ are found. Increasing the fare from $\$ 0$ up until the welfare maximum causes users switching from bus to car. On the one hand, the benefit of bus users is decreased which is compensated by an increased operator revenue of same amount (transfer payment). On the other hand, social welfare is increased due to users switching from bus to car when they produce less congestion or delay costs. In the NDTA model, car congestion is significantly higher than in the TDTA model resulting in longer travel times within the car mode, mainly for large headways and high fares. Therefore switching to car generates less utility for travelers. Since both modes are working at maximum capacity the opportunities of increasing the social welfare by pricing are reduced. For headways of $20 \mathrm{~min} 36 \mathrm{sec}$ or larger a welfare optimal fare of $\$ 0$ is found. Reducing car congestion by shortening bus headway steeply raises social welfare (see Fig. 6a). Finally, for shorter headways the optimal fare is above $\$ 0$. Reduced travel times within the bus mode overcompensate for higher road congestion due to users switching from bus to car.

In this study, bus bunching is not observed to be significant, e.g. buses do not stick to each other or overtake each other. The main reasons for this are: First, buses are not allowed to depart before the scheduled departure time (they can only be delayed). Second, for short scheduled headways, the load factors are lower and buses are also delayed to a lower extent. Whereas, for large headways, load factors are higher and buses are increasingly delayed. However, this applies to all buses and the corridor is not long enough to result in buses falling that much behind the schedule to cause bus bunching. Third, the demand is equally distributed along the corridor. Forth, the share of the peak demand is relatively small. For an analysis of bus bunching with MATSim, see Neumann and Nagel (2010).

Next, we analyse the effects of a binding bus capacity constraint. Assuming randomly distributed activity locations along the corridor, waiting times due to full buses are longer for passengers boarding at the middle of the corridor. Load factors at the beginning and end of the corridor are lower, thus not yielding boarding denials. The number of missed bus trips, depicted in Fig. 8, indicates if buses are working at maximum capacity (some users have to wait for a later bus). In the NDTA model a high number of missed bus trips is found for fares below $\$ 1.00$ with headways between 9 min $21 \mathrm{sec}$ and 1 min $27 \mathrm{sec}$. As Fig. 8b shows for the TDTA model, fares below $\$ 2.00$ combined with headways between $17 \mathrm{~min} 10 \mathrm{sec}$ and $3 \mathrm{~min} 26 \mathrm{sec}$ make the bus mode so attractive that some users are even willing to miss a bus. Short headways reduce the number of passengers per bus, and therefore the number of trips with waiting times larger than one headway is reduced. Increasing the fare for a public transport supply with fully loaded buses leads to less users taking the bus and thereby decreases the number of missed bus trips. Finally, when buses are not working at maximum capacity, either a fare of $\$ 0$ is found to be welfare maximising or the welfare function is almost flat for fares between $\$ 0$ and the optimum. A zero optimal fare means that there is no marginal cost (on top of the av- 
erage user cost) attached to carrying an extra passenger, something that is not longer valid when the bus capacity constraint is binding (see discussion in Tirachini and Hensher (2012)).

\subsubsection{Departure Time Choice and Peak Spreading}

Since waiting times seem to have a major impact on the overall welfare level as well as on the optimal combination of fare and headway, a more detailed analysis of differences between the NDTA and TDTA models is conducted. This provides us with insights into the effects of departure time adaptation to the schedule and peak spreading. In the TDTA model, non-commuters as well as commuters can freely choose their arrival time within a wide time span, therefore, departure times are adjusted to avoid peak periods. Fig. 9 depicts the final time distribution for a headway of $34 \mathrm{~min} 20 \mathrm{sec}$ and a fare of $\$ 1.00$ in the NDTA and the TDTA model. When enabling departure time choice, users disperse around the commuter peaks for two reasons: to maximise their positive utility gained from performing activities and to minimise travel related costs. For example, users benefit from taking the bus at off-peak times. Defining short time windows for arrival at work and an extra penalty for arriving late would have the effect that the activity work has a stronger impact on travel decisions (mode and departure time choice). For example, driving may become more attractive especially if the bus headway is long. Secondly, soft time restrictions in the TDTA model allow users to adapt departure times in order to avoid peak congestion within the bus mode. By adapting departure times, extra waiting times due to fully loaded buses are avoided. Furthermore, long in-vehicle times caused by extended boarding and alighting of other passengers are avoided by departing at off-peak times.

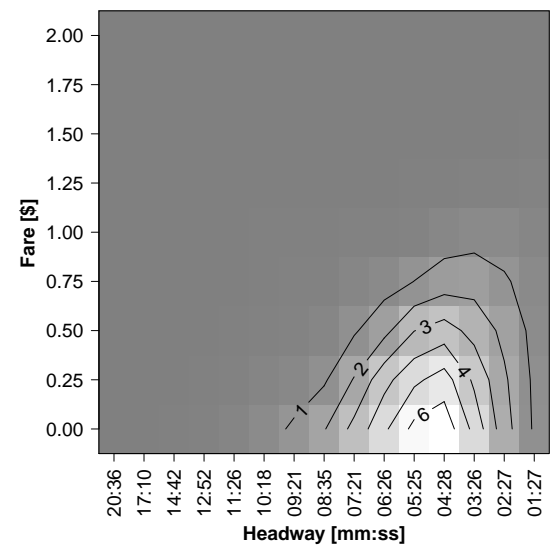

(a) NDTA model

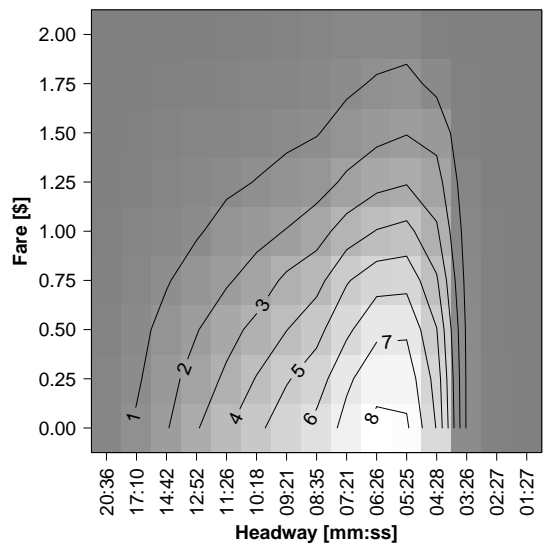

(b) TDTA model

Fig. 8: Number of trips missing at least one bus (average of all random seeds) 


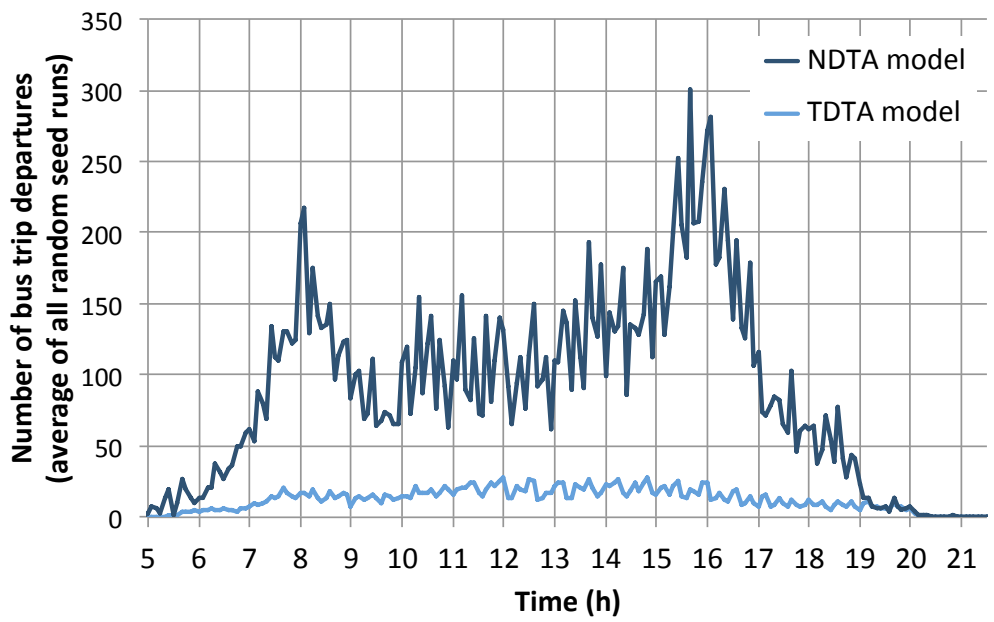

Fig. 9: Final departure time distribution (headway: $34 \min 20$ sec; fare: $\$ 1.00$ )

\subsection{Simulation randomness}

In the previous section, optimal fares and headways are obtained by averaging operator profit and social welfare over 10 random seeds of the simulation model. Fig. 7 depicts the standard deviation of the average welfare over all random seeds and all parameter combinations of headway and fare. There are three effects on the standard deviation that can be observed: First, as described in Sec. 4.1.2, the standard deviation is larger for headway/fare combinations where a large number of passengers cannot board the first arriving bus due to capacity constraints (compare to Fig. 8). This is true for the NDTA and the TDTA model. Second, in the NDTA model, the standard deviation of social welfare is rather high for large headways and high fares. In contrast, for the same parameter combinations, the TDTA model shows a rather small increase in the standard deviation. Presumably, this is due to the fact that in the NDTA model, road congestion is higher than in the TDTA model (see Sec. 4.1.1). Third, combining the observations of the first two effects, the parameter combinations with high standard deviation have in common that users more strongly compete for limited resources, e.g. road capacity or transit vehicles. Randomness in user behavior apparently affects welfare levels of other users rather strongly when resources are scarce. In some situations, the random choice behavior might lead to an efficient use of capacities. In other situations, it might lead to a less efficient use of capacities. This effect is then reflected in a higher standard deviation of social welfare.

The procedure of averaging multiple runs is implemented because we found that different random seeds could result in different combinations of fare and headway that maximise profit and welfare. To illustrate this point, Fig. 10 shows the welfare obtained with three different seeds for a range of fares be- 


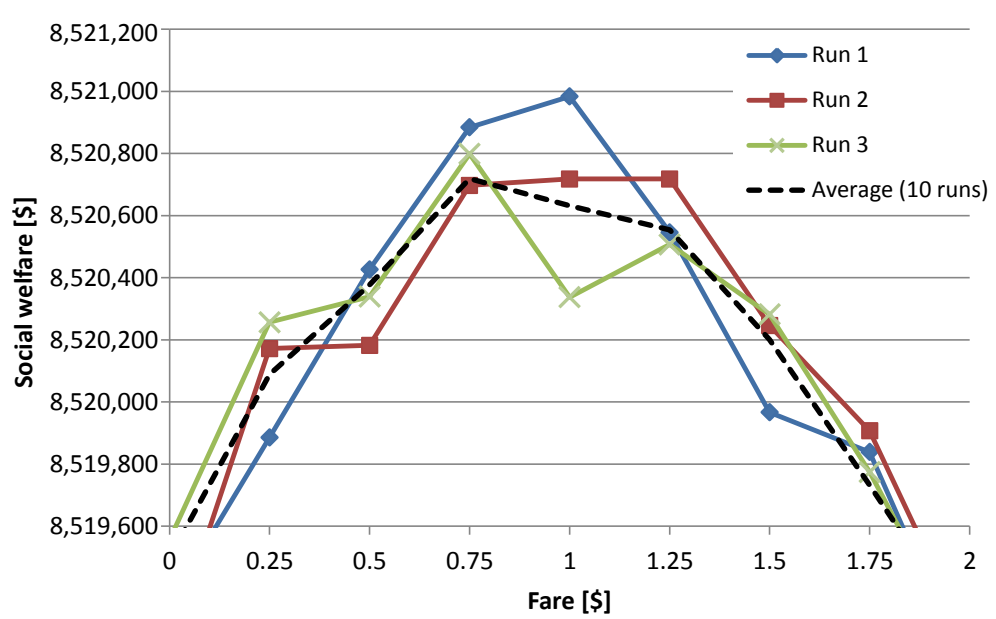

Fig. 10: Randomness in maximum social welfare

tween $\$ 0.25$ and $\$ 1.75$, for a fixed fleet size of three buses. Run 1 reaches a maximum at a fare of $\$ 1.00$. With Run 2 an almost identical welfare level is obtained for fares of $\$ 0.75, \$ 1.00$ and $\$ 1.25$, whereas Run 3 reaches a maximum at $\$ 0.75$ but it also shows a local maximum at $\$ 1.25$. However, when computing the average (over 10 runs), it points to a single maximum at $\$ 0.75$.

Randomness in user behaviour analysed by simulating different random seeds also plays an important role when obtaining the global social welfare maximum, as both optimal fare and headway are sensitive to the random seed chosen. Fig. 11 depicts the number of runs for a total of 50 random seeds in which a particular headway-fare combination is found to maximise welfare for the TDTA model. The total height of a bar indicates for how many random seeds the respective fare is found to be welfare maximising. The colours in each bar indicate for which headway this applies. In the grid search implemented, only two headways are found to maximise welfare of individual seeds, either 3 min $40 \mathrm{sec}$ ( 28 buses) or 4 min $07 \mathrm{sec}$ ( 25 buses). Therefore, we can suggest that the actual optimal headway is likely to be in the range between $3 \mathrm{~min} 30 \mathrm{sec}$ and $4 \mathrm{~min} 30 \mathrm{sec}$. Nevertheless, the range of fares that maximises social welfare for each individual seed is wider, with a likely optimal fare between $\$ 0.4$ and $\$ 0.7$. The most repeated optimal fare is $\$ 0.6$ which was obtained $30 \%$ of times (15 out of 50 seeds, 9 times with 28 buses and 6 times with 25 buses), followed by $\$ 0.4$ obtained $26 \%$ of times, and $\$ 0.7$ obtained $24 \%$ of times. This is an indication that the social welfare function is quite flat around the optimal fare, as shown in Fig. 12, in which results from all 50 seeds are averaged. Figures 11 and 12 suggest that, from a policy perspective, there is scope for other considerations to be taken when deciding the actual fare to be applied within the range $\$ 0.4$ to $\$ 0.7$, as social welfare is practically insen- 


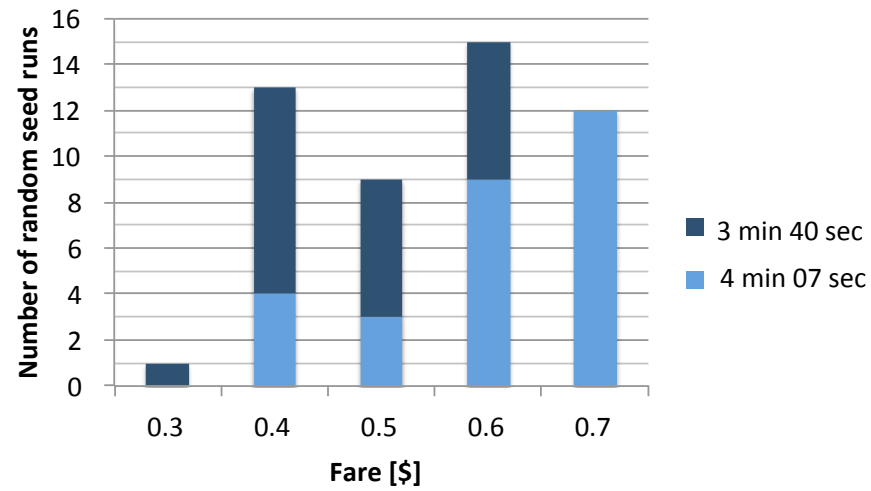

Fig. 11: Number of runs with headways and fares in global welfare maximum, a total of 50 random seed runs, TDTA model

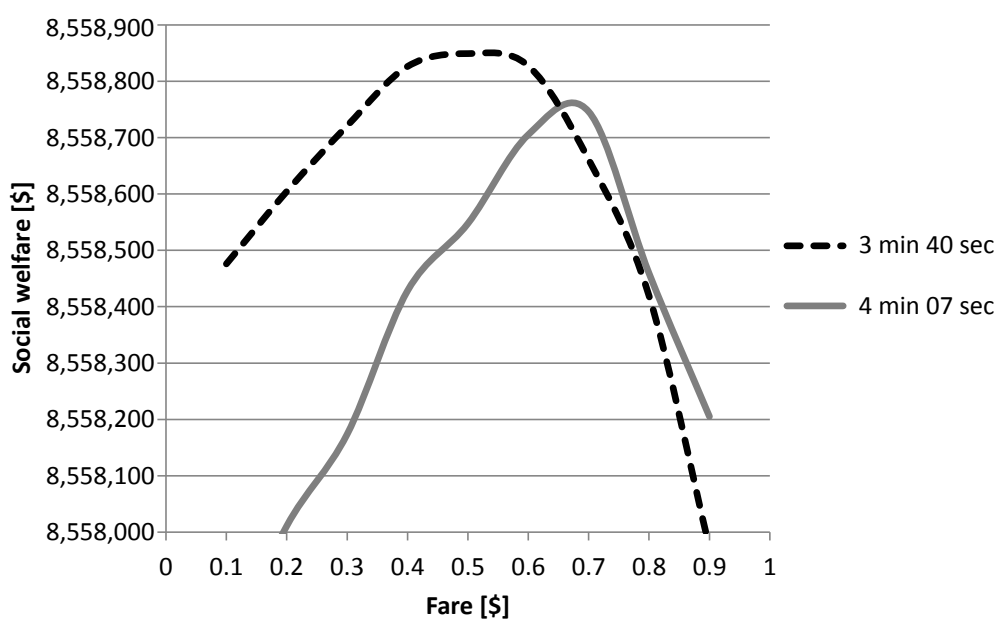

Fig. 12: Social welfare, average over 50 seeds, TDTA model

sitive to any fare on that range (for example, a fare of $\$ 0.4$ increases public transport demand, a fare of $\$ 0.7$ reduces the subsidy required to operate the public transport service).

\section{Conclusions}

In this paper, public transport fare and headway were jointly optimised using an activity-based simulation framework with the objective of maximising operator profit and social welfare (with and without the constraint of maximum subsidy). We simulated the interaction between users - who choose mode 
and departure time according to their activities, timetabling and convenience of the public transport service - and a public transport service provider. Apart from mode choice (travel alternatives are car and bus), we compared the cases in which commuters and non-commuters can adjust departure time as a reaction to changes in bus fare and headway, against the most commonly analysed case in which only mode choice is available (i.e., activity scheduling is fixed). Because the activity patterns of each agent was simulated, relevant implications of public transport supply levels such as waiting times and implications of an active bus capacity constraint were analysed in detail on an agent-by-agent basis. The model was applied to a single bimodal corridor using a demand model and operator cost data from Australia.

The main results of this paper are summarised next. First, unlike traditional analytical models that find single optimal values for decision variables such as bus headway and fare, we obtained a range of values for the optimisation variables due to the randomness in user behaviour that is inherent to our simulation framework. Second, as previously shown in the microeconomic literature of public transport, the maximisation of operator profit and social welfare result in different combinations of (the most likely) optimal headway and fare, and our approach showed that the gap between welfare and profit optimal solutions is smaller when users can adjust their departure time. This is because when users have a fixed activity schedule and cannot adjust departure times, the alternative car mode is increasingly congested, mainly in the peak period, which results in a less elastic public transport demand to price and headway. In addition to that, for parameter ranges around the welfare maximum, departure time choice yields a higher number of bus users. Thus, both, the operator and the users, benefit from departure time adaptation.

Third, analysing the impact of departure time choice, two effects are observed: On the one hand, the ability to reschedule departure times compensates for a larger headway and a higher fare. Enabling departure time choice lets users adapt their departure times according to the bus schedule and on a wider range in order to avoid congestion on the road and on the bus mode (peak spreading), the latter is primarily observed when the bus capacity is reached and waiting times increase due to missed buses. Due to this effect welfare maximising headway and fare are greater when users have the freedom to adjust departure time relative to the case in which their schedules are fixed. On the other hand, the ability to reschedule departure times yields a higher number of bus users and increases the number of trips missing at least one bus. The latter effect shifts the welfare maximum towards a shorter headway relative to the case in which schedules are fixed and bus demand is lower. We provided an in-depth examination of waiting times and bus capacity constraints since they have a major impact on the overall welfare level as well as on the optimal combination of fare and headway. For combinations of headway and fare where the bus mode is attractive enough so that some travelers risk to miss a bus, we found the steepest slope of the welfare function. That is, the more travelers miss a bus, the higher the possible gains by increasing the fare.

The approach presented in this paper can easily be applied to more sophisti- 
cated networks and real world scenarios. Hence, it is an easy-to-use approach that allows to investigate how general the results are for other settings. Our large-scale agent-based simulation model is suitable to analyse the complex interactions between users and transport supply, including several alternatives on public transport service design and road infrastructure for motorised and unmotorised traffic in general. Importantly, the planned extension to realworld scenarios should account for the existence of several activity types, including more diverse work activity types with mixes of commuters with fixed working times, short and wide time windows to work. Different mixes of restrictions on activity durations and start/end times should influence the optimal design of the public transport service (optimal frequency and fare in peak and off-peak periods) and the resulting modal split. Other promising venues of further research are the public transport network design and the inclusion of other sources of disutility, such as travel time variability and passenger crowding.

Acknowledgements We are indebted to Kai Nagel for his helpful comments and support to the development of this project and to three anonymous reviewers for their constructive comments and suggestions. Alejandro Tirachini acknowledges support from Fondecyt, Chile (Grant 11130227) and the Complex Engineering Systems Institute (Grants ICM P-05-004-F, CONICYT FBO16). Previous versions of this paper were presented at the Kuhmo-Nectar Conference on Transportation Economics in Berlin, July 2012 (Kickhöfer et al. 2012) and the Latsis Symposium in Lausanne, September 2012 (Kaddoura et al. 2012).

\section{References}

Ahn, K., 2009. Road pricing and bus service policies. Journal of Transport Economics and Policy 43, 25-53.

Arnott, R., Yan, A., 2000. The two-mode problem: second-best pricing and capacity. Review of Urban \& Regional Development Studies 12, 170-199.

ATC, 2006. National Guidelines for Transport System Management in Australia. Technical Report. Australian Transport Council.

Baskaran, R., Krishnaiah, K., 2012. Simulation model to determine frequency of a single bus route with single and multiple headways. International Journal of Business Performance and Supply Chain Modelling 4, 40-59.

Basso, L. J., Silva, H. E., 2013. Efficiency and substitutability of transit subsidies and other urban transport policies. American Economic Journal: Economic Policy. Forthcoming.

Basso, L., Guevara, C.A.and Gschwender, A., Fuster, M., 2011. Congestion pricing, transit subsidies and dedicated bus lanes: Efficient and practical solutions to congestion. Transport Policy 18, 676-684.

Cetin, N., Burri, A., Nagel, K., 2003. A large-scale agent-based traffic microsimulation based on queue model, in: Proceedings of the Swiss Transport Research Conference (STRC), Monte Verita, CH. See www.strc.ch. Earlier version, with inferior performance values: Transportation Research Board Annual Meeting 2003 paper number 03-4272.

Chang, S.K., Schonfeld, P.M., 1991. Multiple period optimization of bus transit systems. Transportation Research Part B: Methodological 25, 453-478. doi:10.1016/ 0191-2615 (91) 90038-K.

Charypar, D., Nagel, K., 2005. Generating complete all-day activity plans with genetic algorithms. Transportation 32, 369-397.

de Borger, B., Wouters, S., 1998. Transport externalities and optimal pricing and supply decisions in urban transportation: a simulation analysis for belgium. Regional Science and Urban Economics 28, 163-197. 
Dodgson, J.S., Topham, N., 1987. Benefit-cost rules for urban transit subsidies: an integration of allocational, distributional and public finance issues. Journal of Transport Economics and Policy 21, 57-71.

Fernández, R., 2010. Modelling public transport stops by microscopic simulation. Transportation Research Part C 18, 856-868.

Fernández, R., Tyler, N., 2005. Effect of passenger-bus-traffic interactions on bus stop operations. Transportation Planning and Technology 28, 273-292.

Gawron, C., 1998. An iterative algorithm to determine the dynamic user equilibrium in a traffic simulation model. International Journal of Modern Physics C 9, 393-407.

Horni, A., Charypar, D., Axhausen, K.W., 2011. Variability in Transport Microsimulations Investigated for MATSim: Preliminary Results, in: Proceedings of the 11th Swiss Transport Research Conference (STRC).

Horni, A., Nagel, K., Axhausen, K., 2012. High-resolution destination choice in agent-based demand models. Annual Meeting Preprint 12-1989. Transportation Research Board. Washington D.C. Also VSP WP 11-17, see www.vsp.tu-berlin.de/publications.

Jansson, J.O., 1980. A simple bus line model for optimisation of service frequency and bus size. Journal of Transport Economics and Policy 14, 53-80.

Jansson, K., 2010. Public transport policy with and without road pricing, in: 5th KuhmoNectar Conference on Transport Economics.

Jara-Díaz, S.R., Gschwender, A., 2003. Towards a general micoreconomic model for the operation of public transport. Transport Reviews 23, 453-469. doi:\{10.1080/ $0144164032000048922\}$.

Jara-Díaz, S. R., Gschwender, A., 2009. The effect of financial constraints on the optimal design of public transport services. Transportation 36, 65-75.

Kaddoura, I., Kickhöfer, B., Neumann, A., Tirachini, A., 2012. Public transport supply optimization in an activity-based model: Impacts of activity scheduling decisions and dynamic congestion, in: Latsis Symposium 2012 - 1st European Symposium on Quantitative Methods in Transportation Systems, Lausanne, Switzerland. Also VSP WP 12-17, see www.vsp.tu-berlin.de/publications.

Kickhöfer, B., Grether, D., Nagel, K., 2011. Income-contingent user preferences in policy evaluation: application and discussion based on multi-agent transport simulations. Transportation 38, 849-870. doi:10.1007/s11116-011-9357-6.

Kickhöfer, B., Hülsmann, F., Gerike, R., Nagel, K., 2012, in press. Rising car user costs: comparing aggregated and geo-spatial impacts on travel demand and air pollutant emissions, in: Vanoutrive, T., Verhetsel, A. (Eds.), Smart Transport Networks: Decision Making, Sustainability and Market structure. Edward Elgar. NECTAR Series. Also VSP WP 11-16, see www.vsp.tu-berlin.de/publications.

Kickhöfer, B., Kaddoura, I., Neumann, A., Tirachini, A., 2012. Optimal public transport supply in an agent-based model: The influence of departure time choice on operator's profit and social welfare, in: Proceedings of the Kuhmo Nectar Conference on Transportation Economics. Also VSP WP 12-05, see www.vsp.tu-berlin.de/publications.

Kraus, M., 1991. Discomfort externalities and marginal cost transit fares. Journal of Urban Economics 29, 249-259.

Kraus, M., 2003. A new look at the two-mode problem. Journal of Urban Economics 54, $511-530$.

Kraus, M., Yoshida, Y., 2002. The commuter's time-of-use decision and optimal pricing and service in urban mass transit. Journal of Urban Economics 51, 170-195.

Mohring, H., 1972. Optimization and scale economics in urban bus transportation. American Economic Review 62, 591-604.

Nelson, P., Baglino, A., Harrington, W., Safirova, E., Lipman, A., 2007. Transit in Washington, DC: Current benefits and optimal level of provision. Journal of Urban Economics Letters 62, 231-251.

Neumann, A., Nagel, K., 2010. Avoiding bus bunching phenomena from spreading: A dynamic approach using a multi-agent simulation framework. VSP Working Paper 10-08. TU Berlin, Transport Systems Planning and Transport Telematics. URL: https://svn.vsp.tu-berlin.de/repos/public-svn/publications/vspwp/2010/ 10-08. see www.vsp.tu-berlin.de/publications. 
Oldfield, R.H., Bly, P.H., 1988. An analytic investigation of optimal bus size. Transportation Research Part B: Methodological 22, 319-337. doi:10.1016/0191-2615(88) 90038-0.

Parry, I.W.H., Small, K.A., 2009. Should urban transit subsidies be reduced? American Economic Review 99, 700-724

Pels, E., Verhoef, E.T., 2007. Infrastructure pricing and competition between modes in urban transport. Environment and Planning A 39, 2119-2138.

Raney, B., Nagel, K., 2006. An improved framework for large-scale multi-agent simulations of travel behaviour, in: Rietveld, P., Jourquin, B., Westin, K. (Eds.), Towards better performing European Transportation Systems. Routledge, London, pp. 305-347.

Rieser, M., 2010. Adding transit to an agent-based transportation simulation concepts and implementation. Ph.D. thesis. TU Berlin. Also VSP WP 10-05, see www.vsp.tuberlin.de/publications.

Tabuchi, T., 1993. Bottleneck congestion and modal split. Journal of Urban Economics 34, 414-431.

Tirachini, A., Hensher, D.A., 2011. Bus congestion, optimal infrastructure investment and the choice of a fare collection system in dedicated bus corridors. Transportation Research Part B: Methodological 45, 828-844. doi:10.1016/j.trb.2011.02.006.

Tirachini, A., Hensher, D.A., 2012. Multimodal transport pricing: first best, second best and extensions to non-motorized transport. Transport Reviews 32, 181-202.

Tirachini, A., Hensher, D.A., Rose, J.M., 2014. Multimodal pricing and optimal design of public transport services: the interplay between traffic congestion and bus crowding. Transportation Research Part B 61, 33-54.

Vickrey, W., 1969. Congestion theory and transport investment. The American Economic Review 59, 251-260.

Wright, L., Hook, W., 2007. Bus Rapid Transit Planning Guide. Technical Report. ITDP, Institute for Transportation and Development Policy, New York. 